\title{
Case Report \\ Milk Alkali and Hydrochlorothiazide: A Case Report
}

\author{
Babar Parvez, Chinenye Emuwa, Marquetta L. Faulkner, and John J. Murray \\ Department of Internal Medicine, Meharry Medical College, 1818 Albion Street, Nashville, TN 37208, USA \\ Correspondence should be addressed to Chinenye Emuwa, chinemuwa@yahoo.com
}

Received 9 November 2010; Revised 12 February 2011; Accepted 28 March 2011

Academic Editor: Robert A. Kozol

Copyright ( 2011 Babar Parvez et al. This is an open access article distributed under the Creative Commons Attribution License, which permits unrestricted use, distribution, and reproduction in any medium, provided the original work is properly cited.

\begin{abstract}
Hypercalcemia is a relatively common clinical problem in both outpatient and inpatient settings. Primary pathophysiology is the entry of calcium that exceeds its excretion into urine or deposition in bone into circulation. Among a wide array of causes of hypercalcemia, hyperparathyroidism and malignancy are the most common, accounting for greater than 90 percent of cases. Concordantly, there has been a resurgence of milk-alkali syndrome associated with the ingestion of large amounts of calcium and absorbable alkali, making it the third leading cause of hypercalcemia (Beall and Scofield, 1995 and Picolos et al., 2005). This paper centers on a case of over-the-counter calcium and alkali ingestion for acid reflux leading to milk alkali with concordant use of thiazide diuretic for hypertension.
\end{abstract}

\section{Introduction}

Sippy, almost 100 years ago, developed a calcium-laden milk and antacid regimen for the treatment of peptic ulcer disease [1]. The rationale was to neutralize the hyperacidity that was deemed responsible for peptic ulcer disease. The Sippy regimen until the 1970s was used for the treatment of peptic ulcer disease, a disorder that was predominant in middleaged men, when nonantacid treatment was first introduced $[1,2]$. Sippy's original recommendation consisted of the hourly administration of milk and cream together with what became known as the Sippy powders, which were 10 grains ( 1 grain $=65 \mathrm{mg}$ ) each of heavily calcinated magnesia and sodium bicarbonate, alternating with a powder that contained 10 grains of bismuth subcarbonate and 20 to 30 grains of sodium bicarbonate [1].

Hardt and Rivers in 1923 gave a detailed description of the toxicity that was associated with the antacid and milk regimen [3]. The symptoms consisted of nausea, vomiting, headache, dizziness, musculoskeletal pains, and weakness followed by prostration. There was an associated elevation of blood urea nitrogen (BUN) and serum creatinine, alkalosis, and albuminuria. Cope in 1936 first recognized hypercalcemia as a major feature of this toxicity [4]. He also showed a rapid resolution of alkalosis and hypercalcemia after cessation of treatment, but the recovery of renal function was much slower. Fundamentally, the differentiation of milkalkali syndrome from primary hyperparathyroidism was evident due to the absence of hypophosphatemia and the resolution of the hypercalcemia once treatment with antacids was stopped. Burnett et al. in 1949 described a chronic variant of the milk-alkali syndrome in which renal failure was persistent and soft tissue calcifications were extensive [5].

Punsar and Somer in 1963 classified milk-alkali syndrome into three different types: acute, subacute (Cope's syndrome), and chronic (Burnett's syndrome) toxicity [6]. Shortly thereafter, McMillan and Freeman formulated a comprehensive table and compared clinical presentation, biochemical findings, and resolution of the three different types of the milk-alkali syndrome [7]. The subacute form (Cope's syndrome) was seen during therapy with calcium and alkali that had been used intermittently for years. In contrast to the acute form, there was less rapid improvement in symptoms and the recovery of renal function was slower. The chronic form (Burnett's syndrome) occurred after a long history of ingestion of large amounts of calcium and alkali. Presentation of Burnett's syndrome included complains of pruritus, diffuse musculoskeletal symptoms, nephrocalcinosis, and band keratopathy with large soft tissue calcium deposits $[5,8]$. Although symptoms usually improved with the discontinuation of calcium antacids, the resolution of hypercalcemia was slow, especially in patients 
with large soft tissue deposits of calcium. Renal insufficiency often improved but did not resolve completely.

\section{Case Presentation}

Our patient is a 64-year-old Caucasian male who presented to the emergency room (ER) with a 2-week complaint of progressive weakness, dizziness on ambulation, nausea, and per accompanying family members, a deterioration in mental status. In the ER, he was hemodynamically stable, but serum analysis was significant for hypercalcemia of 16.9 with corrected calcium per serum albumin 18.2 (normal 8.4-10.2 milligrams per deciliter $(\mathrm{mg} / \mathrm{dL}$ ), formula for corrected serum calcium $=$ measured serum calcium +0.8 * (normal albumin - measured patient albumin)), alkalosis with bicarbonate 34.6 (normal 21.0-31.0 millimole per liter $(\mathrm{mmol} / \mathrm{L})$, renal insufficiency with BUN 30 (normal 6$20 \mathrm{mg} / \mathrm{dL}$ ) and creatinine 4.0 (normal $0.5-1.2 \mathrm{mg} / \mathrm{dL}$ ), total protein 5.8 (normal 6.2-8.2 g/dL), albumin 3.0 (normal 3.2$5.0 \mathrm{~g} / \mathrm{dL}$ ), phosphorus 3.1 (normal $2.5-4.6 \mathrm{mg} / \mathrm{dL}$ ), WBC 11.5 (normal $4.5-10.0 \mathrm{~K} / \mathrm{cumm}$ ), hemoglobin 14.3 (normal 13.0-17.0 g/dL), hematocrit 40.9 (normal 39.0-52.0), and platelets 341 (normal 140-400 K/cumm). Electrocardiogram (ECG) showed sinus tachycardia at 106 beats per minute, normal PR, and QRS intervals with QT/QTc 304/400 msec. Arterial blood gas showed alkalemia: $\mathrm{pH} 7.48$ (normal 7.357.45), $\mathrm{pCO}^{2} 46$ (normal $35-45 \mathrm{~mm} / \mathrm{Hg}$ ), and $\mathrm{O}^{2}$ saturation 99\% (normal 95-98).

With this physical presentation, hypercalcemia with renal insufficiency and alkalosis, he was admitted to acute medicine floor. Management included aggressive fluid resuscitation with normal saline, acute coronary syndrome rule out, telemetry placement for cardiac arrhythmia monitoring, and workup for the etiology of hypercalcemia. On thorough history and chart review, the patient admitted to taking large quantities of over-the-counter calcium supplementation in the form of TUMS for his chronic acid reflux spanning over 3 decades. Recently, over the past several weeks, due to worsening reflux symptoms, he had increased his daily TUMS from 5-6 tablets to as much as 20-30 tablets per day. $\mathrm{He}$ had previously been seen in a cardiology clinic (6 months prior to this presentation) for followup of hypertension (HTN) and was started on low-dose hydrochlorothiazide $12.5 \mathrm{mg}$ per day. He was seen in a pulmonary clinic for followup of lung nodule (which had previously been worked up as benign) and in a gastrointestinal clinic 2 months after cardiology visit and was noted to have serum $\mathrm{Ca}$ of 11.6. He was counseled extensively on stopping over the counter acid suppression and given prescription of omeprazole $40 \mathrm{mg}$ BID which he decided not to take.

Etiology workup revealed ionized calcium (iCa) at 8.3 (normal $4.48-5.28 \mathrm{mg} / \mathrm{dL}$ ), intact parathyroid hormone (iPTH) $<3.0$ (normal $10-65 \mathrm{pg} / \mathrm{mL}$ ) indicating non-PTHmediated hypercalcemia, parathyroid-hormone-related peptide (PTHrp) at 0 , Vit D $1,25<8$ (normal $18-64 \mathrm{pg} / \mathrm{mL}$ ), and Vit D 25 at 23 (optimum level $25-80 \mathrm{ng} / \mathrm{mL}$ ) ruling out malignancy and hypervitaminosis. Other causes were also ruled out with normal serum thyroid studies, serum protein electrophoresis, chest radiograph, and chest CT showing no new changes and renal ultrasound being benign. Gastroenterology and nephrology consults were obtained to conclude the diagnosis of milk-alkali syndrome and to formulate multidisciplinary plan. He underwent esophagogastroduodenoscopy (EGD) which showed grade IV reflux esophagitis, distal esophageal stricture, gastritis, and erosive duodenitis. Pathologic specimen was reported as benign squamous hyperplasia with negative stain for $H$. pylori. Initial fluid resuscitation was supplemented with IV proton pump inhibitor twice a day and nutrition evaluation and recommendation; all of which resulted in impressive resolution of hypercalcemia and restoration of renal functions to normal thus confirming milk-alkali syndrome. Patient was later discharged home on omeprazole $40 \mathrm{mg}$ twice a day (BID) and hydrochlorothiazide $12.5 \mathrm{mg}$. As followup, he was seen in internal medicine clinic 3 months after discharge with serum $\mathrm{Ca}$ of 10.6, albumin 4.3, improvement in reflux symptoms, and baseline functional status.

\section{Discussion}

In the milk-alkali syndrome, hypercalcemia develops because the input of calcium (dietary intake and intestinal absorption) exceeds the output (primarily renal excretion). About 4 to $60 \mathrm{~g} / \mathrm{d}$ of calcium carbonate has been reported to induce the milk-alkali syndrome, indicating that factors besides calcium intake contribute to the development of the milk-alkali syndrome [9]. Factors that can increase calcium input include increased dietary calcium intake, ingestion of supplemental calcium, enhanced intestinal absorption of calcium usually resulting from stimulation by vitamin D that is present in some calcium supplements, and other dietary factors. Calcium-containing compounds have also been shown to directly increase gastric acid secretion by stimulating the CaSR (calcium-sensing receptor) when ingested orally, which in turn increases the availability of free calcium for absorption $[10,11]$.

It is likely that bone, the primary repository for calcium, increases calcium uptake but becomes saturated during high calcium exposure. The capacity of bone to increase calcium uptake per unit of bone changes with age as does the extent of bone remodeling $[12,13]$. Randall et al. in 1961 gave insight into the time course of this syndrome after observing 40 men with peptic ulcer disease who were treated with milk and either aluminum hydroxide or calcium carbonate [8]. In the milk-carbonate group (12 grams of calcium per day), the mean plasma calcium concentration rose within 24 hours from $10 \mathrm{mg} / \mathrm{dL}$ to $11 \mathrm{mg} / \mathrm{dL}$ ( 2.5 to $2.75 \mathrm{mmol} / \mathrm{L}$ ). In 9 of 20 patients treated for one week, the plasma calcium concentration reached or exceeded $11.3 \mathrm{mg} / \mathrm{dL}(2.8 \mathrm{mmol} / \mathrm{L})$ and, in a few cases, exceeded $12 \mathrm{mg} / \mathrm{dL}(3 \mathrm{mmol} / \mathrm{L})$. The mean plasma bicarbonate concentration rose slightly, but in three of the 20 patients exceeded $31.5 \mathrm{meq} / \mathrm{L}$. The plasma creatinine concentration rose from 1.2 to $1.4 \mathrm{mg} / \mathrm{dL}$ (106 to $124 \mathrm{mmol} / \mathrm{L}$ ) on the third day. The plasma phosphate concentration rose during the first few days. One patient developed the acute milk-alkali syndrome with hypercalcemia preceding the development of renal insufficiency and alkalosis. From this study, it can be concluded that although 
exposure to excessive calcium and alkali ingestion can cause marked increases in serum $\mathrm{Ca}$ and bicarbonate in rare cases, mild intermittent hypercalcemia can be seen in a significant number of patients.

Renal vasoconstriction secondary to hypercalcemia leads to a fall in glomerular filtration rate, and hypercalcemia directly stimulates tubular hydrogen ion secretion and, therefore, bicarbonate reabsorption leading to metabolic alkalosis. The alkalosis helps to maintain hypercalcemia and volume depletion by enhancing the activity of the CaSR and by increasing calcium reabsorption in the distal tubule via the $\mathrm{pH}$-sensitive calcium channel, the transient receptor potential vanilloid member 5 [TRPV5] [17-19]. Volume contraction due to vomiting, diuretics, or the natriuretic effects of hypercalcemia further aggravates hypercalcemia and alkalosis. Marked hypercalcemia can lead to the patient presenting with acute toxicity (nausea, vomiting, weakness, and mental changes with psychosis or depressed sensorium).

After extensive clinical and laboratory evaluation, no evidence of malignant disease or primary hyperparathyroidism was seen in our patient. No cause of hypercalcemia could be identified other than the ingestion of large amount of $\mathrm{CaCO}_{3}$ (calcium carbonate) with concurrent use of thiazide diuretic. Along with the pathophysiology of hypercalcemia secondary to large calcium intake and absorption as mentioned above, thiazide diuretics are known to reduce urinary calcium excretion and produce mild hypercalcemia $[16,17]$. In the kidney, distal convoluted tubule reabsorbs about $8 \%$ of the filtered $\mathrm{Ca}$ load. This occurs via epithelial $\mathrm{Ca}^{2+}$ channels. In the steady state, the cell must extrude all penetrating $\mathrm{Ca}$, which occurs via a $\mathrm{Ca}^{2+}$ ATPase and through $\mathrm{Na}^{+} / \mathrm{Ca}^{2+}$ exchanger located on the basolateral surface of the cells of the distal tubule. Thiazides inhibit the $\mathrm{Na}^{+} / \mathrm{Cl}^{-}$symport in the early distal convoluted tubule, thus causing a decrease in intracellular $\mathrm{Na}$. This, in turn, enhances the activity of the $\mathrm{Na}^{+} / \mathrm{Ca}^{2+}$ exchanger, creating an increased driving for $\mathrm{Ca}$ resorption through the epithelial $\mathrm{Ca}^{2+}$ channels. The final effects increased $\mathrm{Ca}$ reabsorption leading to hypercalcemia. In a novel study, Nijenhuis et al. showed that mice that lacked active distal $\mathrm{Ca}^{2+}$ reabsorption (TRVP5-knockout) developed hypercalcemia with hydrochlorothiazide (HCTZ) treatment and that enhanced passive $\mathrm{Ca}^{2+}$ transport in the proximal tubule rather than active $\mathrm{Ca}^{2+}$ transport in distal convolution explains thiazide-induced hypocalciuria [20].

In conclusion, the ingestion of absorbable calcium, metabolic alkalosis, and concomitant use of thiazide diuretic can produce severe hypercalcemia which can be potentially more life threatening than is generally observed with either agent alone. This must be taken into account while prescribing thiazide diuretics for hypertension to patient with gastric reflux disease due to the ready availability of nonprescription medication containing $\mathrm{CaCO}_{3}$.

\section{Conflict of Interests}

The authors declare that there is no conflict of interests.

\section{Authors' Contribution}

B. Parvez and C. Emuwa contributed equally to the paper.

\section{References}

[1] B. W. Sippy, "Landmark article May 15, 1915: gastric and duodenal ulcer. Medical cure by an efficient removal of gastric juice corrosion. By Bertram W. Sippy," Journal of the American Medical Association, vol. 250, no. 16, pp. 2192-2197, 1983.

[2] J. B. Kirsner and W. L. Palmer, "Alkalosis complicating the Sippy treatment of peptic ulcer," Archives of Internal Medicine, vol. 69, pp. 789-807, 1942.

[3] L. L. Hardt and A. B. Rivers, "Toxic manifestations following the alkaline treatment of peptic ulcer," Archives of Internal Medicine, vol. 31, pp. 171-180, 1923.

[4] C. L. Cope, "Base change in the alkalosis produced by the treatment of gastric ulcer with alkalies," Clinical Science, vol. 2, pp. 287-300, 1936.

[5] C. H. Burnett, R. R. Commons, F. Albright, and J. E. Howard, "Hypercalcemia without hypercalciuria or hypophosphatemia, calcinosis and renal insufficiency," The New England Journal of Medicine, vol. 240, pp. 787-794, 1949.

[6] S. Punsar and T. Somer, "The milk-alkali syndrome. A report of three illustrative cases and a review of the literature," Acta Medica Scandinavica, vol. 173, pp. 435-449, 1963.

[7] D. E. McMillan and R. B. Freeman, "The milk alkali syndrome: a study of the acute disorder with comments on the development of the chronic condition," Medicine, vol. 44, no. 6, pp. 485-501, 1965.

[8] R. E. Randall Jr., M. B. Strauss, and W. F. McNeely, "The milkalkali synfcmme," Archives of internal medicine, vol. 107, pp. 163-181, 1961.

[9] E. S. Orwoll, "The milk-alkali syndrome: current concepts," Annals of Internal Medicine, vol. 97, no. 2, pp. 242-248, 1982.

[10] M. J. Brodie, P. C. Ganguli, A. Fine, and T. J. Thomson, "Effects of oral calcium gluconate on gastric acid secretion and serum gastrin concentration in man," Gut, vol. 18, no. 2, pp. 111-114, 1977.

[11] J. Behar, M. Hitchings, and R. D. Smyth, "Calcium stimulation of gastrin and gastric acid secretion: effect of small doses of calcium carbonate," Gut, vol. 18, no. 6, pp. 442-448, 1977.

[12] V. Matkovic, "Calcium metabolism and calcium requirements during skeletal modeling and consolidation of bone mass," American Journal of Clinical Nutrition, vol. 54, no. 2, 1991.

[13] R. P. Heaney, S. Abrams, B. Dawson-Hughes et al., "Peak bone mass," Osteoporosis International, vol. 11, no. 12, pp. 985-1009, 2000.

[14] S. C. Hebert, S. Cheng, and J. Geibel, "Functions and roles of the extracellular $\mathrm{Ca}^{2+}$-sensing receptor in the gastrointestinal tract," Cell Calcium, vol. 35, no. 3, pp. 239-247, 2004.

[15] P. Ivanovich, H. Fellows, and C. Rich, "The absorption of calcium carbonate," Annals of Internal Medicine, vol. 66, no. 5, pp. 917-923, 1967.

[16] B. A. Lamberg and B. Kuhlback, "Effect of chlorothiazide and hydrochlorothiazide on the excretion of calcium in urine," Scandinavian Journal of Clinical and Laboratory Investigation, vol. 11, pp. 351-357, 1959.

[17] A. M. Parfitt, "Chlorothiazide-induced hypercalcemia in juvenile osteoporosis and hyperparathyroidism," The New England Journal of Medicine, vol. 281, no. 2, pp. 55-59, 1969.

[18] A. M. Patel and S. Goldfarb, "Got calcium? Welcome to the calcium-alkali syndrome," Journal of the American Society of Nephrology, vol. 21, no. 9, pp. 1440-1443, 2010. 
[19] R. A. L. Sutton, N. L. M. Wong, and J. H. Dirks, "Effects of metabolic acidosis and alkalosis on sodium and calcium transport in the dog kidney," Kidney International, vol. 15, no. 5, pp. 520-533, 1979.

[20] T. Nijenhuis, V. Vallon, A. W. C. M. Van Der Kemp, J. Loffing, J. G. J. Hoenderop, and R. J. M. Bindels, "Enhanced passive $\mathrm{Ca}^{2+}$ reabsorption and reduced $\mathrm{Mg}$ channel abundance explains thiazide-induced hypocalciuria and hypomagnesemia," Journal of Clinical Investigation, vol. 115, no. 6, pp. 1651-1658, 2005. 


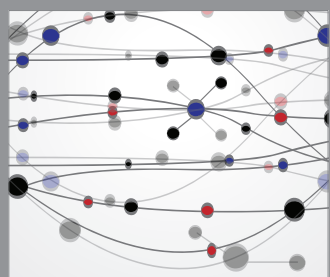

The Scientific World Journal
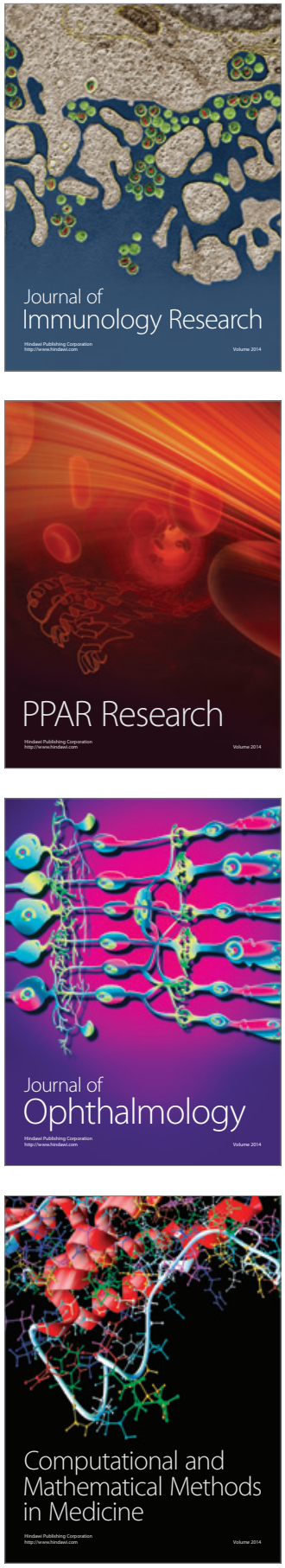



Gastroenterology

Research and Practice
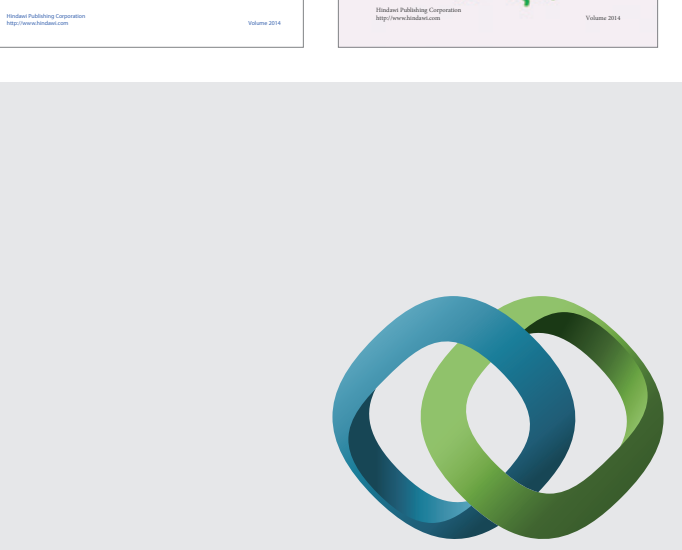

\section{Hindawi}

Submit your manuscripts at

http://www.hindawi.com
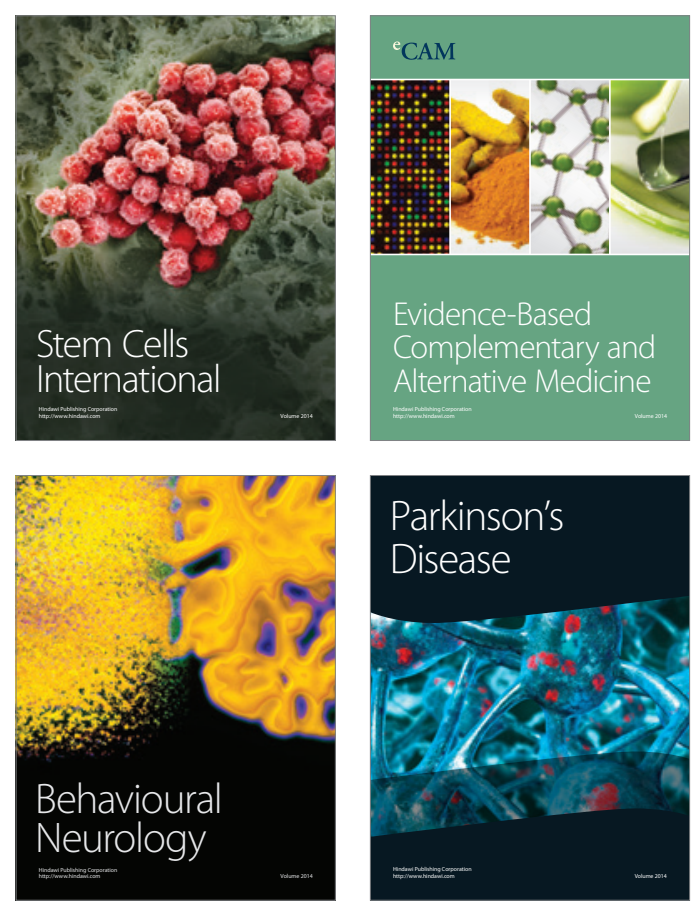

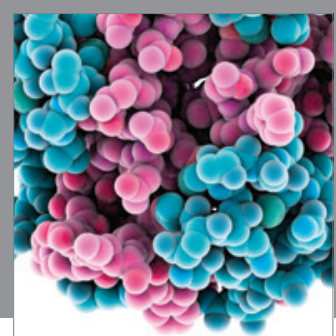

Journal of
Diabetes Research

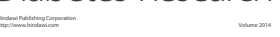

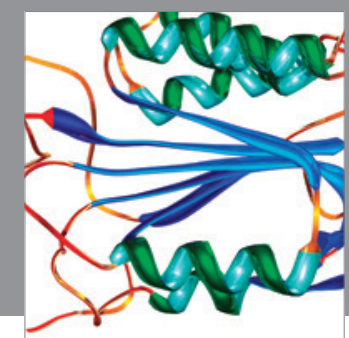

Disease Markers
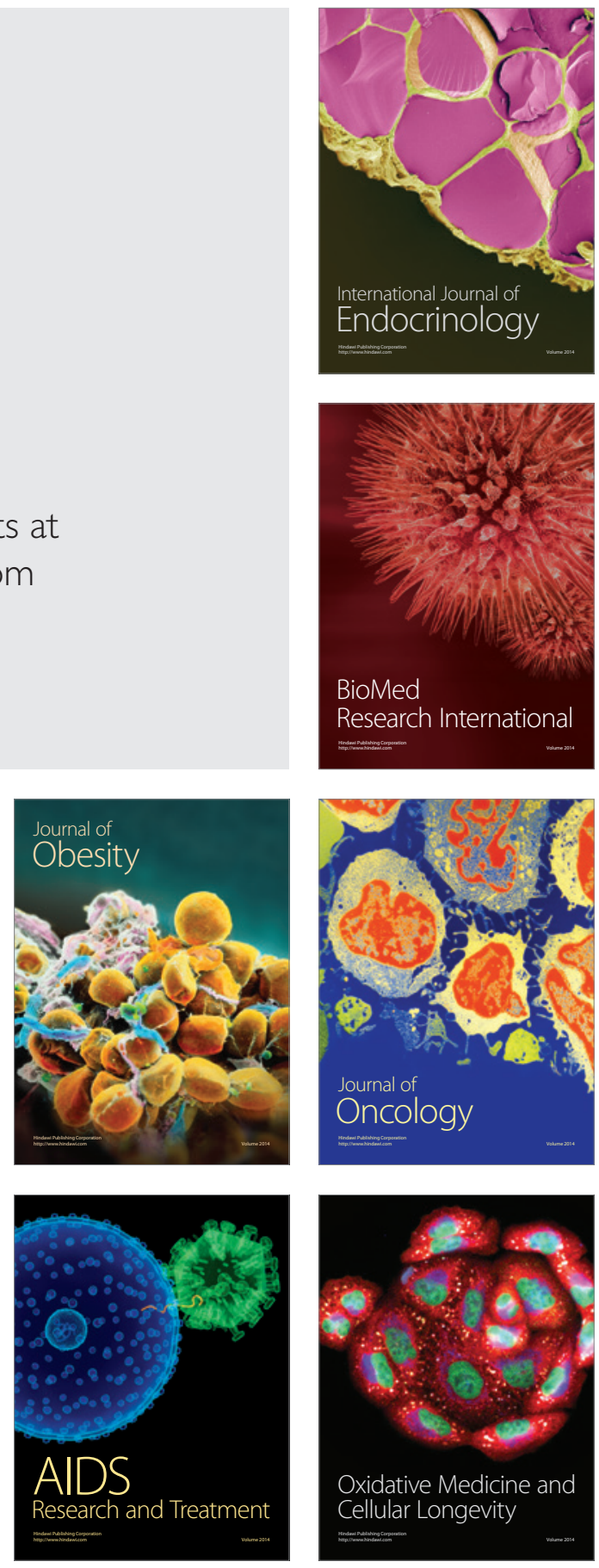